\title{
Chapter 12 \\ Resistance to Integrate Information Systems in Healthcare Service: A Study on Developing Country
}

\author{
Nusrat Jusy Umme and Md. Maruf Hossan Chowdhury
}

\begin{abstract}
Information systems are vital for meeting the service expectations of customers and stakeholders. However, integration of information systems in health service is inhibited due to numerous resistance factors which need to be addressed in order to ensure a quality healthcare service. Despite its significance, there is a paucity of research in addressing the resistance to information technology adoption in the healthcare industry. This relates to two domains: (i) factors contributing to resistance to health information systems (HIS) in developing country contexts and (ii) strategies to mitigate the resistances. This chapter sets out to develop a methodology to address the aforementioned gaps in the literature using an analytical hierarchy process (AHP) integrated quality function deployment (QFD) approach. The developed methodology will be used in a healthcare service providing organization in Bangladesh to identify the factors contributing to resistance to health information systems (HIS) and to determine the most significant strategies to mitigate those resistance factors. This research has significant theoretical, methodological and managerial implications.
\end{abstract}

Keywords Health service · Information systems • Mitigation strategies

Optimization • QFD resistance

\section{N. J. Umme}

School of Information Systems, Curtin Business School, Perth, Australia e-mail: Umme.nusrat@yahoo.com

Md. Maruf Hossan Chowdhury ( $\square)$

Management Discipline Group, UTS Business School, 15 Broadway,

Ultimo, NSW 2007, Australia

e-mail: maruf.chowdhury@uts.edu.au 


\subsection{Introduction}

ICT is an avenue for change, offers effectiveness and efficiency in many facets of the society. By implementing health information systems (HIS), the health sector has been able to improve its health service quality and lessen medical errors (Menachemi and Collum 2011). In the contemporary world, HIS has been successfully adopted by many developed countries in their health service organizations (Mutale et al. 2013). Yet, the HIS in developing countries has not been widely adopted. There are numerous factors that influence the resistance to HIS implementation in developing countries. A review of the relevant, extant literature reveals that issues responsible for reluctance to HIS in developing countries are still underexplored.

Akter et al. (2013) posit that ICT is a leading issue for ensuring health service quality. Likewise, it has been asserted by Chowdhury and Quaddus (2016) that information technology enabled health service design is supportive for sustainable health service systems. They also focused on the significance of information systems (IS) in health service to ensure improved service delivery processes in Bangladesh. Similarly, studies by Braa et al. (2004, 2007) and Lucas (2008) informed the health information systems in developing countries.

The health service industry in Bangladesh still lags behind in the adoption of information technology in delivering their healthcare service, although the advantages of ICT usage in health service are well explored. The reluctance to non-adoption of information and communication technology to deliver and manage health service is contributed by many factors. If such resistances cannot be mitigated, improving health service delivery process is not easy. As a result, it is important to examine the factors responsible for reluctance to HIS implementation in order to identify and mitigate them.

Although the extant literature finds that a lack of ICT infrastructure (Gichoya 2005 ) is the salient factor contributing to the resistance of IS, the literature on resistance shows that the HIS resistance in a developing country context is still under investigated. This gap in the literature encourages the researchers to investigate the following research questions:

1. What are the factors responsible for resistance to HIS in the developing countries?

2. What are the most significant strategies to mitigate the resistance factors?

\subsection{Literature Review}

The following sections include a thorough review of existing literature to identify the factors responsible for resistance to the adoption of health information systems and strategies to mitigate that resistance. 


\subsubsection{Importance of Health Information Systems}

Because of the efficiency, effectiveness, productivity and accuracy gained through technology in business and society, technological dependencies are becoming exponential. In order to satisfy e current business needs, more and more businesses are now keen to utilize technology (Mohammad Alamgir 2012). For improving the service quality in the service industry, technological excellence has also made a substantial contribution (Brynjolfsson 1993). Technological excellence is a vital enabler for service quality which is highly evident in the healthcare industry (Chowdhury and Quaddus 2016). The healthcare industry concerns a broad spectrum of areas which includes primary health care, medical research, pharmaceuticals, etc. (Seninger 1996). Of those, primary health care is one of the most important areas since it provides a direct medical service to a large number of people. The technology used in the healthcare environment is often referred to as health information systems (Hirdes et al. 2008), computerized health information systems (Metsemakers et al. 1992) and hospital information systems (Cline and Luiz 2013; Anderson 1997) by the health service institutions.

It is crucial to implement HIS in the health service organizations. The health service institutions have been able to achieve improved health service, more efficiency, less medical errors and more accuracy with the increased adoption of HIS use (Buntin et al. 2011). Despite the benefits achieved through HIS adoption, it has not yet been diffused in all regions at the same rate. It is evident that the higher adoption of HIS is seen in most developed countries such as the USA, Canada and Australia (Jha et al. 2008; Ludwick and Doucette 2009; Buntin et al. 2011). Developed countries improve their health service by implementing HIS. However, developing countries such as India, Bangladesh and Nepal are still far from adopting HIS across the broader spectrum. There are many important issues which are responsible for the non-adoption of HIS by health service providers in developing countries. Among there are many reasons for the slower adoption of HIS in developing countries, resistance to accept the technology is one of the most significant ones (Kapurubandara and Lawson 2006). The following section enumerates the resistance factors responsible for the non-adoption or slower adoption of HIS.

\subsubsection{Factors Responsible for Resistance to Health Information Systems}

Different studies find that people show resistance to accept new technology both in the context of developing (Knol and Stroken 2001; Kapurubandara and Lawson 2006) and developed countries (Lapointe and Rivard 2005; Bhattacherjee and Hikmet 2007). Existing literature reveals that lack of telecommunication infrastructure, financial constraints (Blaya et al. 2010), lack of IT knowledge and training (Knol and Stroken 2001), lack of skilled human resources (Kapurubandara and 
Lawson 2006) and a few other factors are important drivers towards resistance to technology in the context of developing country. On the other hand, in developed countries, the significant drivers of resistances are related to compatibility, IT-related knowledge (Bhattacherjee and Hikmet 2007) and perceived threat (Lapointe and Rivard 2005). Table 12.1 lists the factors responsible for resistance to HIS.

The lack of an integrated framework to address the possible factors contributing to resistance in the healthcare industry is realized specifically in the context of developing countries, although resistance to technology has caught the attention of scholars for many years. This study, therefore, aims to examine the factors contributing to the resistance of implementing HIS in developing countries.

It is imperative to address the factors responsible for resistance to health information systems, especially in the case of developing countries. Failure to address the factors responsible for resistance to Health Information Systems results in the non-adoption or ineffective implementation of HIS. Therefore, it is crucial to identify the strategies which can mitigate the current resistance problems. Current studies identify a number of strategies to mitigate HIS resistance. It is revealed that ICT Infrastructure development (Detmer 2003), ICT training (Gagnon et al. 2012), Investment in ICT projects (Detmer 2003); effective change management (Markus 2004) and compatible systems (Tung et al. 2008) can mitigate the resistance to integrate the HIS in a developing country context. Table 12.2 presents various strategies for addressing resistance to HIS.

Table 12.1 Factors responsible for resistance to HIS in developing countries

\begin{tabular}{l|l}
\hline Resistance factors & Sources \\
\hline Lack of interest and awareness & $\begin{array}{l}\text { Lapointe and Rivard (2005), Kim and Kankanhalli } \\
(2009)\end{array}$ \\
\hline $\begin{array}{l}\text { Lack of tendency to take } \\
\text { responsibility }\end{array}$ & $\begin{array}{l}\text { Lapointe and Rivard (2005), Kim and Kankanhalli } \\
(2009)\end{array}$ \\
\hline Lack of Internet coverage & Azam (2014) \\
\hline $\begin{array}{l}\text { Lack of required hardware, } \\
\text { software }\end{array}$ & Azam (2014) \\
\hline Inadequate Internet speed & Azam (2014) \\
\hline Power supply interruption & Azam (2014) \\
\hline Lack of IT knowledge & $\begin{array}{l}\text { Venkatesh et al. (2003), Mohammad Alamgir (2012), } \\
\text { Azam (2014) }\end{array}$ \\
\hline $\begin{array}{l}\text { Lack of change management } \\
\text { Lack of compatibility with existing } \\
\text { systems }\end{array}$ & $\begin{array}{l}\text { Anderson (1997), Lorenzi and Riley (2000), Umble } \\
\text { et al. (2003) }\end{array}$ \\
\hline Feeling uncertainty of output & Ali et al. (2016) \\
\hline Strategies to mitigate resistance to Health Information Systems
\end{tabular}

Strategies to mitigate resistance to Health Information Systems 
Table 12.2 Strategies for addressing resistance to HIS

\begin{tabular}{l|l}
\hline Strategies & Sources \\
\hline ICT infrastructure development & Detmer (2003) \\
\hline Imparting ICT training & Gagnon et al. (2012) \\
\hline Investing in access to high speed internet & Chowdhury and Quaddus (2016) \\
\hline Investing in hardware and software & Azam (2014) \\
\hline Awareness creation & Chowdhury and Quaddus (2016) \\
\hline More ICT projects & Detmer (2003) \\
\hline Arranging alternative power supply & Chowdhury and Quaddus (2016) \\
\hline Effective change management & Markus (2004) \\
\hline Compatible system & Tung et al. (2008) \\
\hline Government policy & Azam (2014) \\
\hline Recruiting IT skilled people & Chowdhury and Quaddus (2016) \\
\hline
\end{tabular}

\subsection{Methodology}

This research adopts mixed methods to increase the validity and reliability of data (Creswell and Tashakkori 2007). Aligned with the research objectives, our study adopts both qualitative and quantitative methods. Table 12.3 depicts a summary of the research design. In the qualitative stage, it uses interviews with respondents to identify the resistance factors and the strategies to mitigate resistance to adopt HIS. Data were collected from two decision-makers and three employees of a large public hospital. The average interview time was around 40-60 min. Data collected from the interviews were analysed using content analysis technique.

Table 12.3 Summary of the research design

\begin{tabular}{|c|c|c|}
\hline Research objectives & Data collection & Data analysis \\
\hline $\begin{array}{l}\text { - Identifying the factors } \\
\text { responsible for resistance to } \\
\text { HIS and } \\
\text { - Prioritizing the resistance } \\
\text { factors }\end{array}$ & $\begin{array}{l}\text { - Review of literature on } \\
\text { resistance to HIS } \\
\text { - Interviewing decision makers } \\
\text { and employees using } \\
\text { semi-structured interview for } \\
\text { identifying resistance factors } \\
\text { (WHATs in QFD matrix) } \\
\text { - Comparing the resistance } \\
\text { factors using AHP }\end{array}$ & $\begin{array}{l}\text { - Using content } \\
\text { analysis for } \\
\text { literature and field } \\
\text { study data } \\
\text { - AHP analysis }\end{array}$ \\
\hline $\begin{array}{l}\text { - Identifying the strategies to } \\
\text { mitigate the resistance factors } \\
\text { and selecting the most } \\
\text { important strategies among } \\
\text { them }\end{array}$ & $\begin{array}{l}\text { - Review of existing literature } \\
\text { on mitigation strategies } \\
\text { - Using interview protocol } \\
\text { (semi-structured) to identify } \\
\text { mitigation strategies (HOWs } \\
\text { in QFD matrix) } \\
\text { - Using structured } \\
\text { questionnaire for determining } \\
\text { WHAT-HOW relationship } \\
\text { matrix }\end{array}$ & $\begin{array}{l}\text { - Using content } \\
\text { analysis technique } \\
\text { of literature and field } \\
\text { study data } \\
\text { - QFD analysis }\end{array}$ \\
\hline
\end{tabular}


 \\ N. J. Umme and Md. Maruf Hossan Chowdhury}

Fig. 12.1 Weighting of WHATs using AHP (Saaty 1980)

\begin{tabular}{|c|c|c|c|c|}
\hline & $A_{1}$ & $A_{2}$ & $\ldots$ & $A_{n}$ \\
\hline$A_{1}$ & $W_{1} / W_{1}$ & $W_{1} / W_{2}$ & $\ldots$ & $W_{1} / W_{n}$ \\
\hline $\mathbf{A}=A_{2}$ & $W_{2} / W_{1}$ & $W_{2} / W_{2}$ & $\ldots$ & $W_{2} / W_{n}$ \\
\hline$A_{n}$ & $W_{n} / W_{1}$ & $W_{n} / W_{2}$ & $\ldots$ & $W_{n} / W_{n}$ \\
\hline
\end{tabular}

In the quantitative stage, it uses AHP integrated QFD. The analytic hierarchy process (AHP), developed by Saaty (1980), is a widely used multi-criteria decision modelling technique which deploys a paired comparison method of hierarchical structuring of a decision problem to rank alternative solutions. Figure 12.1 depicts the weighting of decision criteria using AHP.

QFD is an effective technique to translate the customer needs into suitable design requirements/strategies (Kuo et al. 2009). QFD is also used to address specific problems of companies by finding the relationships between organizational problems and strategies to solve those (Chowdhury and Quaddus 2015, 2016). In this chapter, QFD is used to identify the factors responsible for resistance to HIS and develop design requirements/strategies to mitigate those resistance factors. In a typical QFD model, 'design requirements/strategies are referred to as 'WHATs' and 'how to fulfil requirements/solve problems' are referred to as 'HOWs' (Fig. 12.2). In this chapter, WHATs are the resistance factors and HOWs are the strategies to mitigate the resistance factors. A typical QFD model includes some basic inputs such as: (a) requirements/problems-WHATs; (b) importance of WHATs; (c) design requirements/strategies-HOWs; (d) WHAT-HOW relationship matrix; (e) roof matrix (interrelationship among HOWs/Strategies.

The relationship between the resistance factors (WHATs) and corresponding strategies (HOWs) to mitigate the resistance factors is measured as 'no', 'very weak', 'weak', 'moderate', 'strong' and 'very strong' a relationship that is later replaced by the scale $0,1,3,5,7$ and 9 . These weights are used to represent the degree of significance attributed to the relationship. The importance of each strategy is determined by the following equation:

$$
\mathrm{AI}_{j}=\sum_{i=1}^{m} w_{i} R_{i j} \quad \forall j, j=1, \ldots, n
$$


Fig. 12.2 QFD layout
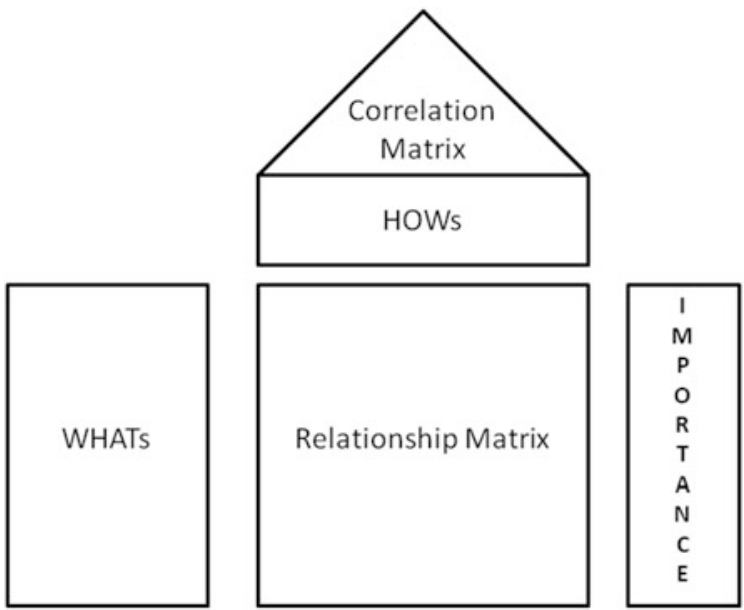

Technical competitive assessment

Absolute value

\section{Relative value}

where,

$\mathrm{AI}_{j}$ absolute importance of $j$ th strategy.

$w_{i} \quad$ weight of the $i$ th resistance factor.

$R_{i j} \quad$ relationship value; extent of mitigating $i$ th resistance factor by $j$ th strategy scaled as $9,7,5,3,1$, or 0 .

$n$ number of strategies.

$m$ number of resistance factors.

The relative importance of strategy $j$ is:

$$
\mathrm{RI}_{j}=\frac{\mathrm{AI}_{j}}{\sum_{j=1}^{n} \mathrm{AI}_{j}}
$$

\subsection{Case Study}

The method as outlined in Table 12.3 was applied in the case of the healthcare industry in Bangladesh. Bangladesh is one of the developing countries in the South-East Asian region with a high density population. According to the 
Population Census Bangladesh 2011, it has a population of 150 million people and among those, $72 \%$ live in rural areas. It is apparent that among 10,000 individuals, there are only 3-4 doctors and the numbers are even less in the rural areas (World Health Organization 2015). Similar to other developing nations, the problem of inadequate information infrastructural facilities in the healthcare seryice is acute in Bangladesh. The quality and accessibility of health service is poor, although health service facilities are available in different locations, including the remote areas. Health service efficiency is important to provide health services to people in a highly populated country like Bangladesh and, it is evident that ICT implementation contributes significantly to the health service efficiency (Buntin et al. 2011). Health service organizations can not only improve their operational efficiency but also its long-term viability with the use of ICT. Therefore, ICT-enabled healthcare service has huge potential in improving healthcare service in developing countries. This is supported by the findings of Chowdhury and Quaddus (2016). Despite the benefit of using health information systems, the adoption, implementation and use of health information systems in Bangladesh are inhibited due to a number of resistance factors. Therefore, this study develops a model that identifies the resistance factors to HIS and strategies to mitigate those resistance factors. Application of the model is operationalized below.

\subsubsection{Identifying the Resistance Factors (WHATs)}

As mentioned earlier, this study adopts a mixed method research where the resistance factors identified from the literature (Table 12.1) were compared with the field study findings to contextualize the resistance factors. Based on the comparison, a list of resistance factors are selected which are presented in Table 12.4 and were finalized for further analysis. Once the list of resistance factors was selected, the importance weights of the resistance factors were then determined using AHP. Table 12.4 presents the resistance factors and their weights. It is apparent from Table 12.4 that lack of awareness about the benefits of HIS is the most important factor creating resistance to HIS, followed by lack of telecommunication infrastructure and lack of IT knowledge and training.

Table 12.4 Resistance factors and their weights

\begin{tabular}{|c|c|c|}
\hline \multirow{3}{*}{$\begin{array}{l}\text { Table 12.4 Resistance } \\
\text { factors and their weights }\end{array}$} & \multirow{2}{*}{\multicolumn{2}{|c|}{\begin{tabular}{l|l} 
AHP weight &
\end{tabular}}} \\
\hline & & \\
\hline & Lack of IT knowledge and training & 0.188 \\
\hline & Implementation cost & 0.100 \\
\hline & Maintenance cost & 0.034 \\
\hline & Lack of telecommunication infrastructure & 0.213 \\
\hline & Interruption in utility supply & 0.056 \\
\hline & Lack of awareness about the benefits of HIS & 0.409 \\
\hline
\end{tabular}


12 Resistance to Integrate Information Systems in Healthcare ...

Table 12.5 Importance score of mitigation strategies

\begin{tabular}{l|l}
\hline Mitigation strategies & Importance score from QFD matrix \\
\hline St1-Awareness building & 0.2596 \\
\hline St2-Imparting training & 0.2145 \\
\hline St3-Investing in ICT infrastructure & 0.1437 \\
\hline St4-Effective change management & 0.1937 \\
\hline St5-Recruiting IT skilled people & 0.1886 \\
\hline
\end{tabular}

\subsubsection{Strategies to Mitigate Resistance Factors (HOWs)}

In line with the research objective, after determining the importance weight of the resistance factors, strategies to mitigate those resistance factors were identified from the interview with the decision makers. The strategies - as identified from the field study - were compared with the strategies identified from the literature (Table 12.2) to determine the final list of strategies as relevant with the context. Table 12.5 presents the strategies relevant to our research context. Once the strategies to mitigate the resistance factors were identified, the decision-makers were then asked to determine the relationship between resistance factors and the corresponding strategies. Figure 12.3 presents the relationship matrix. The relationship matrix is used to determine the most important 'HOWs' or strategies. The relationship between WHATs and HOWs can be measured using the scale 9, 7, 5, 3, 1 and 0 which stand for very strong, strong, moderate, weak, very weak or no relation, respectively. Once the relationship between WHATs and HOWs is determined, the relationship score (in the scale of $9,7,5,3,1$ and 0 ) is multiplied by the weight of corresponding WHAT to derive the final value of each cell in the relationship

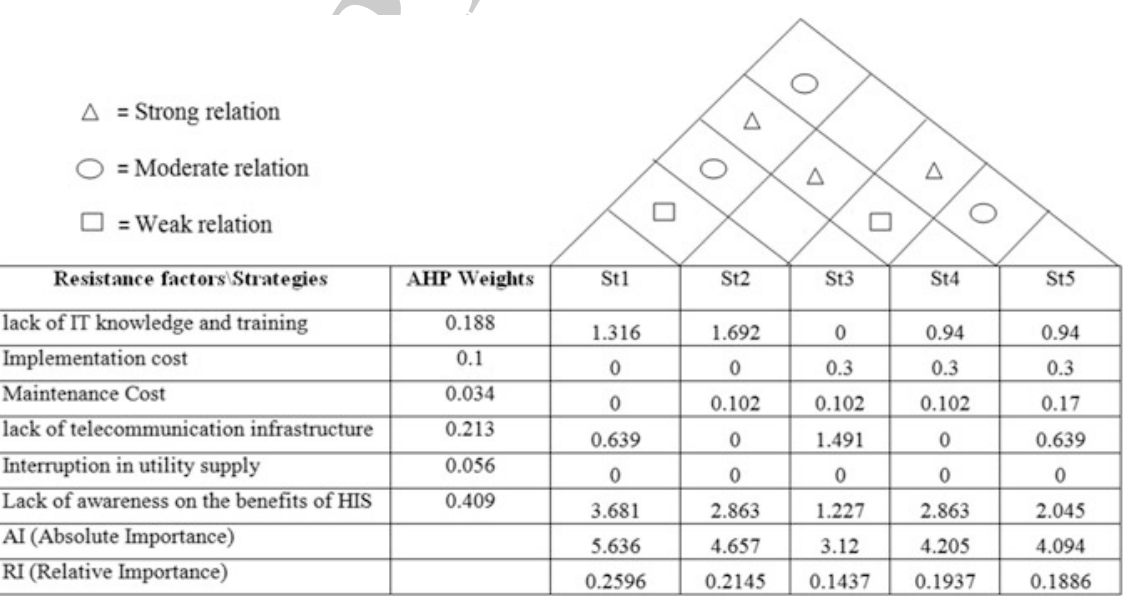

Fig. 12.3 Relationship between resistance factors and corresponding strategies 
matrix. For example, corresponding to strategy 1 and resistance factor 1, the cell value 1.316 in the relationship matrix has derived from the multiplication of the AHP weight of resistance factor $1(0.188)$ with the 'WHATs and HOWs' correlation score 7 (in the scale of 9, 7, 5,3,1 and 0). After determining all the cell values as mentioned, the value of absolute importance (AI) and relative importance (RI) can be determined using Eqs. 12.1 and 12.2 as presented in Fig. 12.3. It is inferred from Fig. 12.3 that the importance weight of awareness building (strategy 1 ) is highest (0.2596), followed by imparting training (strategy 2) (0.2145) and effective change management (strategy 4) (0.1937).

\subsection{Discussion and Implications}

This study finds that 'lack of awareness' about the benefits of health information systems is the most important factor $(40.9 \%)$ resisting the adoption and implementation of HIS. Usually, health service staffs in the less developed countries are reluctant to use new technology as they have limited knowledge about the technology and its benefits to improve services to patients - which is consistent with the study of Chowdhury and Quaddus (2016). In their study on sustainable service design for $m$-health (mobile health) services in Bangladesh, Chowdhury and Quaddus (2016) find that the service providers are not very aware about the customer requirements and some of the health staffs have a lack of knowledge to provide technology enabled services. The second most important resistance factor is a lack of telecommunication infrastructure which accounts for $21.3 \%$ weight. The telecommunication infrastructure is essential to information technology. Most of the cases concerning telecommunication infrastructure in the developing and under developed countries are not well built. As a result, it is difficult to adopt and implement HIS which creates resistance among the managers and the employees to adopt HIS. This finding is consistent with the findings of Azam (2014). This study also finds that the third most important factor resisting HIS is a lack of IT knowledge and training - which accounts for $18.8 \%$ of the total weight. This finding is highly relevant as found in previous studies. Azam (2014), Mohammad Alamgir (2012) and Venkatesh et al. (2003) found that people with a lack of IT knowledge felt reluctant to adopt and implement information systems. Similarly, our study also found that implementation costs, maintenance costs and interruptions in utility supply were the other factors in relation to the resistance of HIS in Bangladesh.

Corresponding to the resistance factors, our study found a number of mitigation strategies. Among the strategies, awareness building was found to be most significant which accounts for $25.96 \%$ of the total weight. In line with this finding, it can be inferred that building awareness among employees and managers is very important to adopt HIS and to create readiness to implement HIS. Previous studies (Kim and Kankanhalli 2009; Lapointe and Rivard 2005) also found that awareness building is salient in mitigating the resistance to adopt information systems. The 
findings also reveal that a strategy for building awareness is effective for mitigating vital challenges such as lack of IT knowledge and training, lack of telecommunication infrastructure and lack of awareness about the benefits of HIS. This is highly relevant, because building awareness about the uses and the benefits of HIS will create interest and expectations among the users and decision-makers to use the systems, develop infrastructure for proper implementation of the systems and train people to run the systems effectively and efficiently. The second most important strategy $(21.45 \%)$ was found to be imparting training-which is effective for mitigating the resistance factors such as: lack of IT knowledge and training, maintenance cost and lack of awareness about the benefits of HIS. Our findings also reveal that the third most important strategy is effective change management which can assist in mitigating most of the resistance factors, except lack of telecommunication infrastructure and interruption in utility supply.

The findings of this study contribute to the existing literature on the health information systems literature - particularly resistance to adopt health information systems in the case of developing countries. The findings of this study identify the most important resistance factors to adopt and implement health information systems in a developing country context. To our knowledge, this has not been studied before and consequently, can make a useful addition to existing literature. This study also determines the strategies to mitigate resistance to health information systems and determines the weight of the strategies to identify the most significant strategies to mitigate the resistance. Previous studies fall short of identifying strategies to mitigate resistance to adopt health information systems in general and in the case of developing countries in particular. With regard to managerial implications, it is proposed that our study outcomes will help health service managers to identify the most important resistance factors to be aware of with regard to the adoption of health information systems in a developing country context. Identifying significant resistance factors will help them to prepare and to mitigate the resistance factors. Further, this study will help managers to determine the most important strategies to mitigate the resistance to adopt health information systems.

\subsection{Conclusion}

This study aims to identify the factors contributing to the resistance to health information systems and strategies to mitigate that resistance. As there is a paucity of current research in addressing the resistance to information technology adoption in the healthcare industry, this study adds value to the existing body of knowledge in health information systems. First, it identifies the most important factors resisting the health information systems. Second, it determines the strategies to mitigate resistance to health information systems. The findings of this study reveal that lack of awareness about the benefits of HIS, lack of telecommunication infrastructure and lack of IT knowledge and training are the most important resistance factors. On the other hand, the study finds that awareness building, imparting training and 
effective change management are the most important mitigation strategies. This study also has limitations that can provide opportunities to pursue further research. The study is conducted on few sample cases, thus empirical verification is needed by operationalizing survey research to ensure the external validity of the findings. Finally, it opens the avenue for further research based on surveys to explore the relationship between the resistance factors and the mitigation strategies. Though this study considers the healthcare service of Bangladesh as a case study, it is proposed that the findings and implications have significance for the healthcare services of other developing countries.

\section{References}

Akter, S., D'Ambra, J., \& Ray, P. (2013). Development and validation of an instrument to measure user perceived service quality of mHealth. Information \& Management, 50(4), 181-195.

Ali, M., Zhou, L., Miller, L., \& Ieromonachou, P. (2016). User resistance in IT: A literature review. International Journal of Information Management, 36(1), 35-43.

Anderson, J. G. (1997). Clearing the way for physicians' use of clinical information systems. Communications of the ACM, 40(8), 83-90.

Azam, M. S. (2014). Diffusion of ICT and SME performance: The mediating effects of integration and utilisation. Doctoral dissertation, Ph.D. Curtin University, Graduate School of Business.

Bhattacherjee, A., \& Hikmet, N. (2007). Physicians' resistance toward healthcare information technology: A theoretical model and empirical test. European Journal of Information Systems, 16(6), 725-737.

Blaya, J. A., Fraser, H. S., \& Holt, B. (2010). E-health technologies show promise in developing countries. Health Affairs, 29(2), 244-251.

Braa, J., Hanseth, O., Heywood, A., Mohammed, W., \& Shaw, V. (2007). Developing health information systems in developing countries: The flexible standards strategy. MIS Quarterly, 31(2), 381-402.

Braa, J., Monteiro, E., \& Sahay, S. (2004), Networks of action: Sustainable health information systems across developing countries. MIS Quarterly, 28(3), 337-362.

Brynjolfsson, E. (1993). The productivity paradox of information technology. Communications of the ACM, 36(12), 66-77.

Buntin, M. B., Burke, M. F., Hoaglin, M. C., \& Blumenthal, D. (2011). The benefits of health information technology: A review of the recent literature shows predominantly positive results. Health Affairs, 30(3), 464-471.

Chowdhury, M. M. H., \& Quaddus, M. A. (2015). A multiple objective optimization based QFD approach for efficient resilient strategies to mitigate supply chain vulnerabilities: The case of garment industry of Bangladesh. Omega, 57(Part A), 5-21.

Chowdhury, M. M. H., \& Quaddus, M. A. (2016). A multi-phased QFD based optimization approach to sustainable service design. International Journal of Production Economics, 171 (Part 2), 165-178. https://doi.org/10.1016/j.ijpe.2015.09.023.

Cline, G. B., \& Luiz, J. M. (2013). Information technology systems in public sector health facilities in developing countries: The case of South Africa. BMC Medical Informatics and Decision Making, 13(1), 1-12.

Creswell, J. W., \& Tashakkori, A. (2007). Developing publishable mixed methods manuscripts. Journal of Mixed Methods Research, 1(2), 107-111.

Detmer, D. E. (2003). Building the national health information infrastructure for personal health, health care services, public health, and research. BMC Medical Informatics and Decision Making, 3(1), 1-12. 
Gagnon, M. P., Desmartis, M., Labrecque, M., Car, J., Pagliari, C., Pluye, P., et al. (2012). Systematic review of factors influencing the adoption of information and communication technologies by healthcare professionals. Journal of Medical Systems, 36(1), 241-277.

Gichoya, D. (2005). Factors affecting the successful implementation of ICT projects in government. The Electronic Journal of e-Government, 3(4), 175-184.

Hirdes, J. P., Ljunggren, G., Morris, J. N., Frijters, D. H., Soveri, H. F., Gray, L., et al. (2008). Reliability of the InterRAI suite of assessment instruments: A 12-country study of an integrated health information system. BMC Health Services Research, 8(1), 277.

Jha, A. K., Doolan, D., Grandt, D., Scott, T., \& Bates, D. W. (2008). The use of health information technology in seven nations. International Journal of Medical Informatics, 77(12), 848-854.

Kapurubandara, M., \& Lawson, R. (2006). Barriers to adopting ICT and e-Commerce with SMEs in developing countries: An exploratory study in Sri Lanka. University of Western Sydney, Australia, 2005-2016, [online]. http://www.collecter.org/archives/2006_December/07.pdf. August 30, 2016.

Kim, H. W., \& Kankanhalli, A. (2009). Investigating user resistance to information systems implementation: A status quo bias perspective. MIS Quarterly, 33(3), 567-582.

Knol, W. H. C., \& Stroeken, J. H. M. (2001). The diffusion and adoption of information technology in small-and medium-sized enterprises through IT scenarios. Technology Analysis \& Strategic Management, 13(2), 227-246.

Kuo, T. C., Wu, H. H., \& Shieh, J. I. (2009). Integration of environmental considerations in quality Function deployment by using fuzzy logic. Expert Systems with Applications, 36(3), 7148-7156.

Lapointe, L., \& Rivard, S. (2005). A multilevel model of resistance to information technology implementation. MIS Quarterly, 29(3), 461-491.

Lorenzi, N. M., \& Riley, R. T. (2000). Managing change: An overview. Journal of the American Medical Informatics Association, 7(2), 116-124.

Lucas, H. (2008). Information and communications technology for future health systems in developing countries. Social Science and Medicine, 66(10), 2122-2132.

Ludwick, D. A., \& Doucette, J. (2009). Adopting electronic medical records in primary care: Lessons learned from health information systems implementation experience in seven countries. International Journal of Medical Informatics, 78(1), 22-31.

Markus, M. L. (2004). Technochange management: Using IT to drive organizational change. Journal of Information Technology, 19(1), 4-20.

Menachemi, N., \& Collum, T. H. (2011). Benefits and drawbacks of electronic health record systems. Risk Management and Healthcare Policy, 4, 47-55.

Metsemakers, J. F., Höppener, P., Knottnerus, J. A., Kocken, R. J., \& Limonard, C. B. (1992). Computerized health information in The Netherlands: A registration network of family practices. British Journal of General Practice, 42(356), 102-106.

Mohammad Alamgir, H. (2012). Adoption, continued, and extended use of radio frequency identification (RFID) technology: Australian livestock industry. Doctoral dissertation. Curtin University.

Mutale, W., Chintu, N., Amoroso, C., Awoonor-Williams, K., Phillips, J., Baynes, C., et al. (2013). Population health implementation and training-Africa health initiative data collaborative. Improving health information systems for decision making across five Sub-Saharan African countries: Implementation strategies from the African health initiative. BMC Health Services Research, 13(Suppl 2), S9.

Population Census Report Bangladesh. (2011). Available at 〈http://www.sid.gov.bd/wp-content/ uploads/2013/01/BANGLADESH-at-a-glance-Census-2011.pdf $\rangle$. URL (Accessed May 1, 16).

Saaty, T. L. (1980). The analytic hierarchy process. NY, USA: McGraw-Hill. Cook, W. D. \& Seiford, L. M. (1978). Priority ranking and consensus formation. Management Science, 24, $1721-1732$.

Seninger, S. F. (1996). Health service industry highlights. Montana Business Quarterly, 34(1), $23-24$. 
Tung, F. C., Chang, S. C., \& Chou, C. M. (2008). An extension of trust and TAM model with IDT in the adoption of the electronic logistics information system in HIS in the medical industry. International Journal of Medical Informatics, 77(5), 324-335.

Umble, E. J., Haft, R. R., \& Umble, M. M. (2003). Enterprise resource planning: Implementation procedures and critical success factors. European Journal of Operational Research, 146(2), 241-257.

Venkatesh, V., Morris, M. G., Davis, G. B., \& Davis, F. D. (2003). User acceptance of information technology: Toward a unified view. MIS Quarterly, 27(3), 425-478. 